\title{
Some Aspects of Emotional Functioning in Hard-of-Hearing Students
}

\author{
Bibigul Zheksembaevna Almukhambetova ${ }^{1, *}$, Elmira Daauletkhanovna Bazhenova ${ }^{1}$, Arzigul \\ Ismailovna Shuzhebaeva ${ }^{1}$, Saule Myrzabekovna Dyusembinova ${ }^{2}$ and Anuar \\ Toktamysovich Isabaev ${ }^{2}$
}

\author{
${ }^{1}$ Department of Pedagogy and Psychology, Zhetysu State University named after I. Zhansugurov, \\ Kazakhstan \\ ${ }^{2}$ Department of Natural Sciences, Zhetysu State University named after I. Zhansugurov, Kazakhstan
}

\begin{abstract}
Input at early ages, hearing loss can compromise emotional health and cause learning difficulties. Nonetheless, there are relatively few relevant investigations addressing emotional development in hearing-impaired students. The current research intended to compare the self-reported emotional functioning in hearing and hearingimpaired students in order to examine whether there are differences between them. A cross-sectional study was conducted on 94 hard-of-hearing individuals and 104 typical hearing subjects between 16 and 24 years of age from three institutions in Kazakhstan. The overall happiness, life satisfaction, level of anxiety, and emotional preferences were assessed with the Subjective Happiness Scale, Satisfaction with Life Scale, State-Trait Anxiety Inventory, and a questionnaire developed by Dodonov, respectively. The data were subjected to the multivariate analysis of variance. Children and adolescents with hearing loss are reportedly more likely than typical hearing peers to experience various psychosocial difficulties, antisocial disorders, and reactions. However, in the present research, both groups were similar regarding the emotional preferences, apart from the altruistic scale, which was significantly higher $(P<0.001)$ in hearingimpaired participants relative to their hearing counterparts. When compared to normal-hearing persons, hard-of-hearing respondents had higher scores $(P<0.001)$ for trait and state anxiety while having lower scores $(P \leq 0.001)$ for satisfaction with life and overall happiness, which could be seen as a matter of concern. As a potential future line of research, throwing more light on other aspects of emotional functioning in learners with hearing loss might be necessary. To our knowledge, this is the first report on the State-Trait Anxiety Inventory performed on hearing-impaired youth. The findings from this investigation could be of practical help to practitioners working with hard-of-hearing students, providing additional information on their emotional well-being.
\end{abstract}

Keywords: Anxiety, education, happiness, hearing loss, life satisfaction.

\section{INTRODUCTION}

A hard-of-hearing individual is one having mild to severe hearing loss (25-90 decibels). The etiology of hearing impairment is convoluted, varying from genetic to environmental prerequisites, and it may occur throughout the lifespan [1, 2]. Input at early ages, hearing loss, can imperil one's linguistic, intellectual, and social capacities, leading to several learning difficulties and, consequently, inadequate academic performance [3-6]. Moreover, research evidence suggests that the social-emotional well-being of hearing-impaired persons, particularly adolescents, is affected negatively by limiting contact with peers and other social interaction issues, resulting in increased loneliness ratings, depression symptoms, lower quality of life, and mental disorders [7, 8].

When [9] asked students to match three musical excerpts with fear, sadness, or happiness, they revealed a significantly worse emotional perception of

*Address correspondence to this author at the Department of Pedagogy and Psychology, Zhetysu State University named after I. Zhansugurov, ul. Zhansugurova 187a, Taldykorgan, 040009, Kazakhstan;

E-mail: almuhambetbibigul@gmail.com sadness in congenital hearing-loss subjects as opposed to normal-hearing participants $(P<0.001)$. The authors attribute this to the no-sound environment the deaf students had been exposed to so that their ability to decode emotional meaning was reduced.

In 2016, Global Research on Developmental Disabilities Collaborators [10] recorded a hearing loss in 15.5 million children under five years of age, making it second only to vision loss. The burden of the disease is higher in low- and middle-income countries compared to high-income countries due to their weak healthcare systems [11]. Unfortunately, statistical data in Kazakhstan are often presented only through speeches by high-level officials instead of official reports. This is also in the case of statistics on Kazakhstanis with hearing impairments. The Vice Minister of Labor and Social Protection of the Republic of Kazakhstan stated [12] that, as of 2018, the number of hearing-impaired children aged below 18 in Kazakhstan was 4.5 thousand, which is $0.08 \%$ of the total child population. Among the Third World countries, Kazakhstan was classified under the group of those with a low level of legal provisions for people with disabilities [13]. One of the consequences of this 
situation is the deficiency of the equipment required for appropriate audiological screening, concomitantly with well-trained audiologists and speech therapists in Kazakhstan [14].

In terms of world practice, there has been, on the one hand, increasing engagement of the international scientific community in problems related to learners with special educational needs [15]. What is more, based on a structured literature review carried out in the field of deaf education research, [16] outlined that, owing to the shared understanding on the interrelatedness of social interactions and emotional health, social skills interventions and programs for children and youth with hearing loss tend to address both the academic and socioemotional needs? On the other hand, [17] identified a shortage of high-quality research addressing emotional development in hearing-impaired students, which was regarded as a critical obstacle to releasing their academic and career potential.

Upon review of the current literature devoted to the emotional functioning of Kazakhstani students with hearing impairment, we, in turn, have to concede that it was not possible for us to find relevant publications on the topic, even though the comparative evaluation of emotional self-reflection in youth with hearing loss and typical hearing subjects may contribute additional evidence and assist academic advisors working with hard-of-hearing students, thus potentially facilitating steps toward building improved educational systems. Therefore, the authors of the present study took up the task of investigating differences between perceptions of hard-of-hearing and normal-hearing students towards their emotional functioning.

\section{METHODOLOGY}

\section{Participants}

The sample was composed of 94 hard-of-hearing individuals (51 males; 43 females) and 104 subjects having hearing within the normal range, of which 59 were males, while 45 were females. A chi-square test resulted in the $p$-value of 0.726 for gender by hearing status. The participants were students between 16 and 24 years of age from Zhetysu State University named after I. Zhansugurov (Taldykorgan, Kazakhstan, $\mathrm{n}=122$ ), Zhambyl Medical College (Taraz, Kazakhstan, $\mathrm{n}=39$ ), and Taldykorgan Higher Polytechnic College (Taldykorgan, Kazakhstan, n=37).

\section{Procedure and Measures}

The survey study took place over a period between September 2020 and December 2020. Having reviewed our research project, the Ethics Council at Karaganda Technical University came to the conclusion that the research procedures do not pose any risk to participants and approved the ethical aspects of the study (ethics approval number: 2020-06№4-UCPI) in August 2020, after which the survey invitations were distributed. Among those who had agreed to participate, normal-hearing students were surveyed remotely through electronic mail, while small groups of hearing-impaired participants were invited to fill out paper versions of the questionnaires at their institutions in a pullout model of instruction three to four times a week during about forty minutes per day. Members of the research team who are certified specialists in pedagogy and psychology were designated to coordinate and conduct the data collection process. All responses were voluntary and anonymous. The respondents were duly informed about the object of the investigation. The following tests were administered to all participants.

Emotional preferences were assessed with a questionnaire developed by Dodonov [18] made up of fifty items measured on a three-point Likert scale ( $0=$ no; $1=$ do not know; $2=y e s$ ).

The anxiety screening was executed through the State-Trait Anxiety Inventory (STAI) test (adaptation by Khanin) that comprises two 20-item scales: the state anxiety scale (STAI-S), measuring the current level of anxiety intensity, and the trait anxiety scale (STAI-T) evaluating a generalized anxiety propensity. Both scales are scored on a four-point Likert scale: from 'not at all to 'very much so' for STAI-S, and from 'almost never' to 'almost always' for STAI-T. The overall possible score on each scale is between 20 and 80 points, with $20-37,38-44$, and $45-80$ indicating no or low, moderate, and high anxiety, respectively [19].

Global life satisfaction was measured using a Russian version of the Satisfaction with Life Scale (SWLS) by Dr. Diener, consisting of five items, each formulated as a seven-point Likert scale ranging from 1 ('strongly disagree') to 7 ('strongly agree'). The higher the summary score, the greater life satisfaction [20].

The overall happiness was assessed by means of a four-question Subjective Happiness Scale (SHS) adapted for a Russian-speaking population, with 
Table 1: Results of Multivariate Analysis of Variance for Comparing the Observed Variables among Hard-of-Hearing and Normal-Hearing Students

\begin{tabular}{|c|c|c|c|c|}
\hline Source Term & Degrees of Freedom & Mean Square & F-Ratio & 13.08 \\
\hline \hline Altruistic & 1 & 109.792 & 1.89 & 0.000 \\
\hline Communicative & 1 & 18.698 & 2.43 & 0.121 \\
\hline Gloric & 1 & 23.987 & 0.07 & 0.792 \\
\hline Praxical & 1 & 0.546 & 0.272 \\
\hline Pugnic & 1 & 12.700 & 0.48 & 0.491 \\
\hline Romantic & 1 & 4.588 & 0.64 & 0.426 \\
\hline Gnostic & 1 & 5.694 & 3.77 & 0.605 \\
\hline Aesthetic & 1 & 2.719 & 0.054 \\
\hline Hedonic & 1 & 37.837 & 1.16 & 0.689 \\
\hline Acquisitive & 1 & 237.567 & 14.78 & 0.000 \\
\hline Trait anxiety & 1 & 2447.536 & 248.13 & 0.000 \\
\hline State anxiety & 1 & 489.135 & 11.72 & 0.001 \\
\hline Life satisfaction & 1 & 370.450 & 15.48 & 0.000 \\
\hline Subjective happiness & 1 & & \\
\hline
\end{tabular}

response options based on a seven-point Likert scale. A higher final score indicates a higher level of subjective happiness [21].

\section{Data Analysis}

First, the data obtained were screened for missing data, following which the multivariate analysis of variance was run with NCSS 2021 statistical package (NCSS, LLC, Kaysville, Utah, USA). After a Bonferroni correction of 0.05 divided by the number of the dependent variables, the alpha level was set at 0.004 . Figures were generated from the raw data using GraphPad Prism version 8.0 (GraphPad Software Inc., La Jolla, California, USA).

\section{RESULTS AND DISCUSSION}

Table 1 compares the examined emotional variables in students with and without hearing impairments.

Therefore, it appears that there were significant differences between typically hearing and hearingimpaired groups in SWLS, SHS, both STAI scales, and the altruistic propensity within the Dodonov's test.

As seen in Figure 1, hearing and hard-of-hearing respondents were comparable for all scales in the emotional preferences questionnaire, except the altruistic one, which was $31.0 \%$ higher $(P<0.001)$ for the participants with hearing loss. The highest-scoring emotion dominants in both groups were praxical $(62.9 \%$ of hearing students and $63.9 \%$ of hearingimpaired subjects) and gnostic $(61.9 \%$ of hearing respondents and $65.3 \%$ of hearing-impaired students) variables. The lowest values in hearing subjects were recorded for altruistic (48.2\%) and communicative $(48.9 \%)$ scales, while in hard-of-hearing learners, the lowest scores were for hedonic (46.0\%) and acquisitive $(47.3 \%)$ variables.

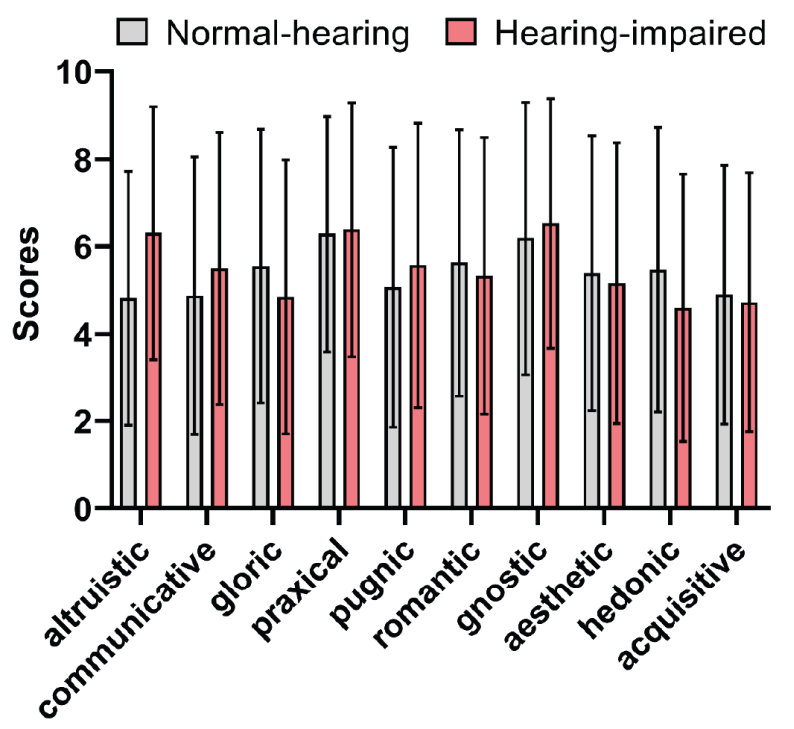

\section{Emotional preferences}

Figure 1: Results of the Dodonov's test among hard-ofhearing and normal-hearing students. The top of each box displays the mean, and the error bars display the standard deviation. 
Both recruited groups had a relatively moderate degree of trait anxiety, as measured by the STAI-T, but there were significantly higher scores for the hearingimpaired surveyees $(6.0 \%$; $P<0.001)$ relative to the participants having no hearing loss. As regards the STAI-S scale, the values reported by the hard-ofhearing group indicated a moderate level of transitory anxiety (STAI-S) being at a significantly higher rate (20.9\%; $P<0.001)$ when compared to the reference group with normal-hearing students showing low state anxiety (Figure 2).

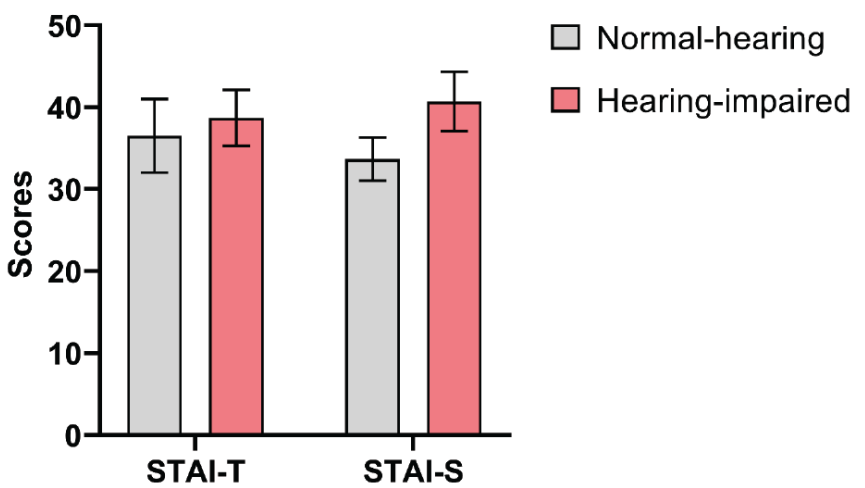

Figure 2: Results of the State-Trait Anxiety Inventory among hard-of-hearing and normal-hearing students. The top of each box displays the mean, and the error bars display the standard deviation. STAI-T=the trait anxiety scale. STAI$S=$ the state anxiety scale.

Accordingly, mean scores in SWLS and SHS for the hearing-impaired students were $14.4 \%$ and $15.3 \%$ lower than those for the normal-hearing respondents (Figure 3). Those differences were statistically significant $(P \leq 0.001)$.

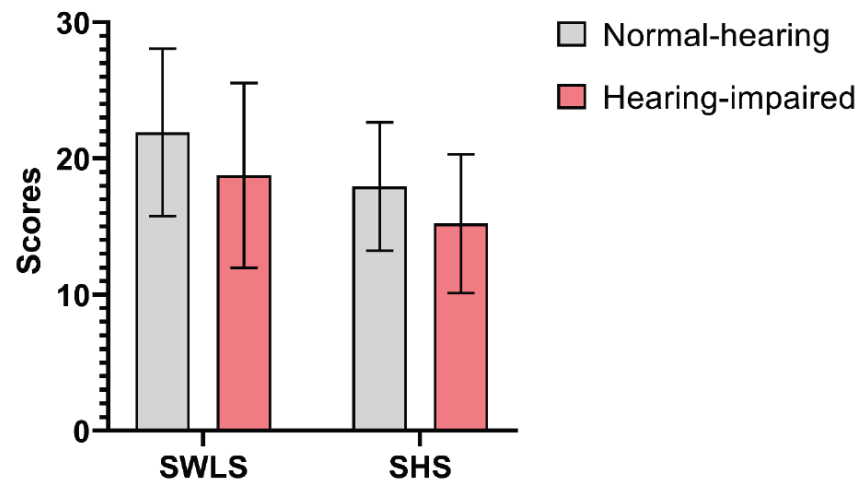

Figure 3: Results of the Satisfaction with Life Scale (SWLS) and the Subjective Happiness Scale (SHS) among hard-ofhearing and normal-hearing students. The top of each box displays the mean, and the error bars display the standard deviation.

Thus, SWLS showed the condition of being slightly dissatisfied with life in hard-of-hearing respondents and little life satisfaction in hearing controls, while there was overall neutral happiness in both groups as measured by SHS.

\section{DISCUSSION}

Past evidence has shown that a range of psychosocial difficulties along with atypical emotion socialization may occur more commonly in hearingimpaired people as compared with the normal-hearing sample, particularly on account of reduced auditory perception and limited access to the social environment $[22,23]$. There have been some indications that children and adolescents with hearing loss are more likely than typical hearing peers to experience antisocial disorders and reactions, exhibiting less altruistic and helping behaviors [24, 25]. In respect of the research described herein, hearing and hard-ofhearing students were comparable in terms of emotional preferences, and those hearing-impaired even exceeded their typical hearing counterparts in altruistic propensity.

Similarly, when normal-hearing and deaf (cochlear implants users) adolescents along with their parents and teachers were surveyed [26] through the Strengths and Difficulties Questionnaire, there were no group differences in the mental health of the youths, including a scale encompassing prosocial behavior problems, such as poor altruism. In turn, [27] argues that early diagnosis and rehabilitation of hearing loss available nowadays reduce its negative effects on the development of a person, including social-emotional development.

According to some reports, individuals with hearing impairment tend to have higher rates of various internalizing symptoms, including anxiety, as opposed to their typical hearing counterparts $[28,29]$. It is consonant with the present study.

To our knowledge, this is the first report on the STAI test performed on hearing-impaired youth. Recently, [30] undertook a prospective longitudinal investigation of an association between hearing loss and anxiety using STAI, but the study population was composed of subjects aged 65 and above. As a result, the authors established the hypothesized association, and social isolation along with communication difficulties was suggested as possible contributing factors.

Results obtained from SWLS and SHS tests performed within our research are partially consistent with findings of a previous study [31] employing SWLS, 
where participants recognized as healthy people were significantly more satisfied with their life $(P<0.01)$ relative to a group of people with disabilities, which comprised $35.4 \%$ deaf or hard-of-hearing persons. On the other hand, [32] surveyed 1,226 students with psychological, cognitive, and physical disabilities (including hearing loss) or no disabilities through University New Student Census. No significant differences in life satisfaction were revealed between individuals reporting physical disabilities and others. Moreover, no significant correlation $(P>0.05)$ between life satisfaction and hearing was found in research by [33].

Regarding limitations of the current work, the major one is that the reports of the surveyees may have suffered from subjectivity. Besides, only certain emotional dimensions were evaluated. Therefore, conclusions should be drawn carefully. Nonetheless, the research presented herein contributes to elucidating emotional functioning in hard-of-hearing students. The anxiety scores obtained in the present study could be seen as a matter of concern, so we would say that this is an important task for future teachers and other practitioners to facilitate reducing the levels of social exclusion in learners with hearing loss. From an educational perspective, it was inferred from a systematic review [34] that social media have reportedly had a positive effect on the learning of deaf and hard-of-hearing students by virtue of enhanced interaction, learning motivation, support, and feedback. Therefore, it might be recommended to professionals working with hearing-impaired students to incorporate social media in relevant activities.

\section{CONCLUSION}

It can be summarized that normal-hearing and hardof-hearing students were similar in regard to their emotional preferences, though hard-of-hearing surveyees appeared to perceive themselves as more altruistic when compared with their typical hearing counterparts. As opposed to normal-hearing persons, hard-of-hearing respondents tend to evince more trait and state anxiety while having lower satisfaction with life and overall happiness. However, those differences were not dramatic, so the findings are not conclusive and merit further investigation. Our results are partially in concordance with previously published evidence. The findings from this investigation could be of practical help to practitioners dealing with hard-of-hearing students, providing additional information on their emotional well-being. It was recommended to integrate social media into relevant practices. As a potential future line of research, throwing more light on other aspects of emotional functioning in learners with hearing loss might be necessary.

\section{ACKNOWLEDGMENTS}

The authors wish to thank Sergey Sergeevich Kozhevnikov for providing the English-language version of the manuscript.

\section{REFERENCES}

[1] Liaqat K, Hussain S, Bilal M, et al. Further evidence of involvement of TMEM132E in autosomal recessive nonsyndromic hearing impairment. J Hum Genet 2020; 65: 187-92.

https://doi.org/10.1038/s10038-019-0691-4

[2] Tingang EW, Noubiap JJ, Fokouo JV, et al. Hearing impairment overview in Africa: the case of Cameroon. Genes 2020; 11(2): 1-18.

[3] Ariapooran S. Mathematics motivation, anxiety, and performance in female deaf/hard-of-hearing and hearing students. Commun Disord Q 2017; 38: 172-8. https://doi.org/10.1177/1525740116681271

[4] Baglama B, Haksiz M, Uzunboylu H. Technologies used in the education of hearing-impaired individuals. Int $\mathrm{J}$ Emerg Technol Learn 2018; 13: 53-63.

[5] https://doi.org/10.3991/ijet.v13i09.8303

[6] Fang BX, Cen JT, Yuan T, et al. Etiology of newborn hearing impairment in Guangdong province: 10-year experience with screening, diagnosis, and follow-up. World J Pediatr 2020; 16: 305-13.

https://doi.org/10.1007/s12519-019-00325-4

[7] Wezzie S, Fayiah M, Gwayi S. Challenges faced by learners with hearing impairments in a special school environment: $A$ case study of Embangweni primary school for the deaf, Mzimba district, Malawi. World J Vocat Educ Train 2020; 2: 21-36.

[8] Lukomski J. Deaf college students' perceptions of their social-emotional adjustment. J Deaf Stud Deaf Educ 2007; 12: 486-94.

https://doi.org/10.1093/deafed/enm008

[9] Lassale C, Vullo P, Cadar D, Batty GD, Steptoe A, Zaninotto $P$. Association of inflammatory markers with hearing impairment: The English longitudinal study of aging. Brain Behav Immun 2020; 83: 112-9.

https://doi.org/10.1016/j.bbi.2019.09.020

[10] Mazaheryazdi M, Aghasoleimani M, Karimi M, Arjmand P Perception of musical emotion in the students with cognitive and acquired hearing loss. Iran J Child Neurol 2018; 12: 418.

[11] Global Research on Developmental Disabilities Collaborators. Developmental disabilities among children younger than five years in 195 countries and territories, 1990-2016: A systematic analysis for the Global Burden of Disease Study 2016. Lancet Glob Health 2018; 6: e1100-21. https://doi.org/10.1016/S2214-109X(18)30309-7

[12] Bussé AM, Hoeve HL, Nasserinejad K, Mackey AR, Simonsz HJ, Goedegebure A. Prevalence of permanent neonatal hearing impairment: a systematic review and Bayesian meta-analysis. Int J Audiol 2020; 59: 475-85. https://doi.org/10.1080/14992027.2020.1716087

[13] Mamyrkhanova M. V Kazahstane rastyot chislo detej s invalidnost'yu. Kursiv [Internet]. 2019 Apr 15 [cited 2021 May 4]. Available from: https://kursiv.kz/news/obschestvo/201904/v-kazakhstane-rastet-chislo-detey-s-invalidnostyu 
[14] Jones N, Presler-Marshall E, Stavropoulou M. Adolescents with disabilities. Enhancing resilience and delivering inclusive development. Overseas Development Institute; 2018 [cited 2021 May 4]. Available from: https://www.odi.org/sites/ odi.org.uk/files/resource-documents/12323.pdf

[15] Kosherbayeva L, Medeulova A, Hailey D, Yermukhanova L, Uraz R, Aitmanbetova A. Influence of a health technology assessment on the use of pediatric cochlear implantation in Kazakhstan. Health Policy Technol 2018; 7: 239-42. https://doi.org/10.1016/j.hlpt.2018.06.002

[16] Vodopivec JL, Bagon S. Motivation for using ICT and pupils with learning difficulties. Int J Emerg Technol Learn 2016; 11: 70-5.

https://doi.org/10.3991/ijet.v11i10.5786

[17] Cawthon SW, Fink B, Schoffstall S, Wendel E. In the rearview mirror: Social skill development in deaf youth, 1990-2015. Am Ann Deaf 2018; 162: 479-85.

[18] Luckner JL, Movahedazarhouligh S. Social-emotional interventions with children and youth who are deaf or hard of hearing: A research synthesis. J Deaf Stud Deaf Educ 2019; 24(1): 1-10.

https://doi.org/10.1093/deafed/eny030

[19] Belousova A, Belousova E. Gnostic emotions of students in solving of thinking tasks. Int J Cogn Res Sci Eng Educ 2020; 8(2): 27-34.

https://doi.org/10.5937/IJCRSEE2002027B

[20] Ekinci M, Gölboyu BE, Dülgeroğlu O, et al. The relationship between preoperative anxiety levels and vasovagal incidents during the administration of spinal anesthesia. Rev Bras Anestesiol 2017; 67: 388-94. https://doi.org/10.1016/j.bjane.2016.07.017

[21] Jovanović V, Lazić M, Gavrilov-Jerković V. Measuring life satisfaction among psychiatric patients: measurement invariance and validity of the satisfaction with life scale. Clin Psychol Psychother 2020; 27: 378-83.

https://doi.org/10.1002/cpp.2434

[22] Chien CL, Chen PL, Chu PJ, Wu HY, Chen YC, Hsu SC. The Chinese version of the Subjective Happiness Scale: Validation and convergence with multidimensional measures. J Psychoeduc Assess 2020; 38: 222-35. https://doi.org/10.1177/0734282919837403

[23] Mekonnen M, Hannu S, Elina L, Matti K. Socio-emotional problems experienced by deaf and hard of hearing students in Ethiopia. Deafness Educ Int 2015; 17: 155-62. https://doi.org/10.1179/1557069X15Y.0000000002

[24] Tsou Y-T, Li B, Kret ME, Sabino da Costa I, Rieffe C. Reading emotional faces in deaf and hard-of-hearing and typically hearing children. Emotion 2020; Advance online publication [cited 2021 May 4]. Available from: https://doi.apa.org/doiLanding?doi=10.1037\%2Femo0000863
[25] Stevenson J, McCann D, Watkin P, Worsfold S, Kennedy C. The relationship between language development and behaviour problems in children with hearing loss. J Child Psychol Psychiatry 2010; 51(1): 77-83.

https://doi.org/10.1111/j.1469-7610.2009.02124.x

[26] Ahmadi H, Daramadi PS, Asadi-Samani M, Sani MRM. Effectiveness of group training of assertiveness on social anxiety among deaf and hard of hearing adolescents. Int Tinnitus J 2017; 21(1): 14-20. https://doi.org/10.5935/0946-5448.20170004

[27] Huber M, Kipman U. The mental health of deaf adolescents with cochlear implants compared to their hearing peers. Int $J$ Audiol 2011; 50: 146-54. https://doi.org/10.3109/14992027.2010.533704

[28] Most T, Michaelis $H$. Auditory, visual, and auditory-visual perceptions of emotions by young children with hearing loss versus children with normal hearing. J Speech Lang Hear Res 2012; 55: 1148-62.

https://doi.org/10.1044/1092-4388(2011/11-0060)

[29] Michael R, Attias J, Raveh E. Cochlear implantation and social-emotional functioning of children with hearing loss. $J$ Deaf Stud Deaf Educ 2019; 24(1): 25-31. https://doi.org/10.1093/deafed/eny034

[30] Long J, Attuquayefio T, Hudson JL. Factors associated with anxiety symptoms in Australian deaf or hard of hearing children. J Deaf Stud Deaf Educ 2021; 26(1): 13-20. https://doi.org/10.1093/deafed/enaa035

[31] Cosh S, Naël V, Carrière I, et al. Bidirectional associations of vision and hearing loss with anxiety: Prospective findings from the three-city study. Age Ageing 2018; 47: 582-89. https://doi.org/10.1093/ageing/afy062

[32] Bendíková E, Nemček D, Kurková P, Lubkowska W, Mroczek B. Satisfaction with Life Scale analyses among healthy people, people with noncommunicable diseases and people with disabilities. Fam Med Prim Care Rev 2018; 20: 210-3. https://doi.org/10.5114/fmpcr.2018.76917

[33] Dong S, Lucas MS. Psychological profile of university students with different types of disabilities. J Coll Stud Dev 2014; 55: 481-5. https://doi.org/10.1353/csd.2014.0044

[34] Mulderrig KE, Rogers S. Deaf cultural identification, cochlear implants, and life satisfaction. Can Acoust 2019; 47(3): 20-1.

[35] Toofaninejad E, Zaraii Zavaraki E, Dawson S, Poquet O, Sharifi Daramadi P. Social media use for deaf and hard of hearing students in educational settings: A systematic review of literature. Deafness Educ Int 2017; 19: 144-61. https://doi.org/10.1080/14643154.2017.1411874

\section{https://doi.org/10.6000/2292-2598.2021.09.03.3}

(C) 2021 Almukhambetova et al.; Licensee Lifescience Global.

This is an open access article licensed under the terms of the Creative Commons Attribution Non-Commercial License (http://creativecommons.org/licenses/by-nc/3.0/) which permits unrestricted, non-commercial use, distribution and reproduction in any medium, provided the work is properly cited. 